\title{
Derecho y justicia: práctica y hecho social. Entrevista a Lidia Casas Becerra
}

\author{
Law and Justice: Social Practice and Fact. \\ Interview with Lidia Casas Becerra \\ Direito e justiça: prática e fato social. \\ Entrevista com Lidia Casas Becerra
}

Entrevista realizada a Lidia Casas* por Mariela Delgado Silva**

18 de mayo de 2020 .

Mariela Delgado: En primer lugar, es un honor para la Revista Temas Sociológicos poder contar con su testimonio y aporte en este $\mathrm{N}^{\circ}$ 26 dedicado a reflexionar sobre el derecho y la justicia. Pensamos en usted dada su gran trayectoria como abogada en derechos humanos y también por el escenario actual que estamos atravesando.

Mariela Delgado: Quiero partir la entrevista enfocándome en su trayectoria profesional. ¿Usted nos podría narrar su carrera como abogada y cómo comenzó a vincularse fuertemente con materias de derechos humanos?

$1 \quad$ Directora del Centro de Derechos Humanos de la Universidad Diego Portales; es Licenciada en Urban and Regional Planning, University of Saskatchewan, Canadá; Licenciada en Derecho por la Universidad Diego Portales (1999); cuenta con un LLM (Magíster) en Derecho de la University of Toronto y es Doctora en Derecho de la University of Ottawa, Canadá; fue recipiente de la Ford Foundation Reproductive Health Fellowship; recibió la beca de IDRC (International Development Research Center (Canadá) por el Global Health Research Initiative; recibió el premio de la International Planned Parenthood Federation de la Región Hemisferio Occidental (2001) por su destacada defensa de la planificación familiar, además de la distinción del Día de la Mujer 2017 de ComunidadMujer por su destacada trayectoria en la promoción y defensa de los derechos humanos de las mujeres; fue miembro del Grupo Asesor - Gender and Rights Advisory Group- del Departamento de Salud Reproductiva de la Organización Mundial de la Salud (2009-2010 y 2013-2015); y ha sido consultora para el Centro de Justicia de las Américas, CEJA, y la GTZ, organismo de cooperación de Alemania. E-mail: lidia.casas@udp.cl

2 Estudiante de Sociología en la Universidad Católica Silva Henríquez y asistente de gestión editorial de la Revista Temas Sociológicos. E-mail: marielandelgadosilva@gmail.com 
Lidia Casas: Me cuesta pensarme solo como abogada, porque yo tengo una formación profesional previa al derecho, y creo que eso me acerca al derecho tradicional con una mirada distinta. Yo estudié planificación regional y urbana en Canadá y trabajé, además, en centros para mujeres inmigrantes y refugiadas en Toronto; también, en la misma ciudad, en una clínica jurídica y comunitaria para personas de bajos recursos. Ese último trabajo me acercó de una manera definitiva al derecho. Pese a que ese trabajo lo había iniciado en un centro, habiéndome desempeñado como trabajadora comunitaria en ayuda de mujeres migrantes, allí, en algunos momentos, teníamos que acompañar a mujeres a agencias administrativas, porque se les negaba su derecho a seguridad social, empleo, bienestar social u otros, existiendo una brecha lingüística súper importante. Y también trabajé en la clínica jurídica que es para toda la comunidad, no solo para inmigrantes, canadienses y todo tipo de grupos de inmigrantes en una comunidad determinada. Uno de los elementos principales de mi tarea, porque en Toronto y Ontario estaba permitido, era que los trabajadores comunitarios legales pudieran representar a sus clientes en tribunales administrativos, en general, pero también en tribunales en temas relacionados con arrendamiento. Ese fue mi acercamiento al derecho. Entonces, mi primera etapa pre-abogada es trabajando con la comunidad y con los sectores que uno puede decir que están en una situación de desventaja —en el caso de las mujeres, era súper evidente-, mujeres migrantes, refugiadas y, luego, también con personas de menores recursos que requieren acceso a asistencia legal a través de esta asistencia comunitaria.

Posteriormente, volví a Chile en el año 1990 y, desde Canadá, postulé a la Escuela de Derecho. Mis colegas en la clínica de Canadá me habían dicho que yo estaba malgastando mi energía siendo trabajadora legal comunitaria, porque hacia el mismo trabajo que ellas, pero ganaba una porción de lo que ganaban los abogados. Pero eso me ponía en una disyuntiva: si yo iba a estudiar derecho en Canadá, yo me quedaba en Canadá. Esa iba a ser una decisión consciente de quedarme ahí para el resto de mi vida. Ya había pasado el plebiscito de 1988, ya estábamos en procesos muchos más claros de recuperación democrática y tomo la decisión de volver a Chile, y postulo desde Canadá a la Diego Portales, donde fui admitida por admisión especial. Entonces, cuando entré, no era una estudiante de pregrado común y corriente, 
ya tenía un carrete previo. Era mayor, en general, que el resto de mis compañeros; había unos cuantos también que habían ingresado por admisión especial; y uno que también había vivido en exilio y, por lo tanto, ahí existía una cierta comunidad.

Eso de, digamos, pasar por la Facultad en el año 90 y los años siguientes fue importante - como procesos míos, también, de reconciliación con el país. Había en esa facultad mucha discusión y las personas, profesores, que estaban ahí habían sido exonerados de la Universidad de Chile en la dictadura, entonces había un ambiente grato. Fui tempranamente ligándome a trabajar con Jorge Correa Sutil. Mis temas, casi de facto, se fueron dando en áreas de los derechos humanos y mientras estaba en la universidad siendo estudiante, hice también investigación, fui trabajando en organizaciones de mujeres feministas y desarrollando alguna investigación que fuera pionera en América Latina en ese minuto. Todo mi trabajo fue en esa conexión: entre lo que yo traía de antes, más lo que estaba incorporando, así se fue dando de una forma natural.

Mariela Delgado: El origen siempre fue lo social y el derecho se convirtió en una herramienta.

Lidia Casas: Absolutamente.

Mariela Delgado: Desde que usted comienza a estudiar derecho, ¿recuerda algunos hitos profesionales que hayan sido importantes para su carrera?

Lidia Casas: Bueno, sí. A mí me carga decirlo, pero creo que es honesto también hacerlo. En términos de carrera investigativa, como profesional, fue un primer trabajo en un curso electivo que tenía un título como de tres líneas y que lo impartía en ese minuto quien es el actual rector de la UDP, Carlos Peña, que se llamaba algo así como: "Aspectos políticos, antropológicos y sociales del derecho", una cosa súper ampulosa, y yo hice una investigación, un ensayo; y ese ensayo terminó con una excelente calificación y fue finalmente publicado en una revista que existía en ese minuto, una de estudiantes. Miembros del tribunal constitucional vieron el artículo y querían que yo les entregara mis fuentes bibliográficas, básicamente. Me acuerdo que en ese minuto me dijeron: "No. Usted no entrega nada, le deben pagar por su trabajo", y a partir de ese trabajo yo comienzo a investigar. 
Vivía hacía muy pocos años en Chile, no conocía a mucha gente, y así fue como yo ingresé al mundo de las organizaciones de mujeres. Entonces, es el paso de la Facultad, el paso de un trabajo y la publicación que dan inicio a un momento en particular, y ciertamente esa investigación después da paso a otra; hago una investigación pionera y que creo que es lo que me marca para el desarrollo en mi trabajo investigativo, el cual era analizar expedientes judiciales sobre mujeres que habían sido procesadas por aborto en una cárcel de mujeres.

Yo estaba ya en los últimos años de la Facultad y logré obtener una autorización para ingresar a la cárcel, ver los expedientes de quienes habían defendido a esas mujeres. Creo que eso me marcó. Primero, porque era una investigación dura en el sentido del lugar mismo, el locus donde tenía que ir era la cárcel. Estaba encerrada sola en una sala, buscaba entre papeles, entre expedientes en unas cajas horrorosas, esas antiguas cajas de cartón. En ese entonces eran enormes y uno ahí tenía que ir buscando y sacando expediente por expediente hasta encontrarlos. Y esa sensación de estar encerrada e ir leyendo las historias de esas mujeres, yo creo que me marcó muchísimo en términos de cómo mirar el derecho en acción y con mujeres con rostro. No era una cuestión abstracta de leyes, sino de mirar finalmente a esas mujeres que se paseaban por ahí y que al fin y al cabo estaban indicadas como abortistas.

Ahí me tocó hacer dos entrevistas que fueron muy difíciles para mí. Una fue a una mujer que hacía abortos con sonda y conversamos durante una hora. La mujer nunca dejó de llorar, porque su clienta se había muerto producto del aborto, entonces fue muy, muy duro. Y la otra fue a una chica muy joven, de diecinueve años, que se había venido a trabajar como trabajadora de casa particular y estudiaba de noche. Ella siempre estuvo muy contenida y muy digna. Sus padres no sabían que ella estaba presa y solo al final de la entrevista ella me da las razones por las cuales en realidad se hace el aborto. Cuando yo le pregunto: "Bueno, si quieres contarme algo más...", su algo más era su propia vivencia de haber sido una hija no deseada por el padre, no reconocida por su padre y siempre haber sido tratada muy distinto del resto de sus hermanas. Entonces, era la sensación de haber tenido un ex que había rechazado la paternidad, que se había desentendido completamente de eso; ella sentía que podía repetir la historia con ese hijo que espe- 
raba. Yo diría que eso marca, fíjate. No siendo abogada, marca para mí una trayectoria profesional.

Mariela Delgado: Está de frente con las experiencias.

\section{Lidia Casas: ¡Claro!}

Mariela Delgado: Usted se ha desarrollado como académica. En base a eso, ¿qué relaciones encuentra usted entre su vida académica y su profesión? ¿Qué tan importante logra ser su vida académica para usted en relación con su profesión?

Lidia Casas: El derecho, en tanto pensarlo como ejercicio legal de la profesión, lo he usado como herramienta. Lo he usado, desde el punto de vista del litigio, como un dispositivo de movilización legal y también para la defensa de derechos específicos de mujeres. No es que mi vida académica esté solo en la investigación, sino que cuando he sentido que hay una necesidad vital de defender una causa, esas herramientas del litigio para mí están ahí y yo creo que las he usado en algunas ocasiones. También uno se da cuenta de los años, cómo pasan, y que fue en el año 2001, o sea van a ser casi 20 años, cuando comienza a discutirse en Chile la incorporación del anticonceptivo de emergencia y se presentan los primeros recursos de protección en contra del registro.

Yo trabajaba, independiente de mi trabajo en la universidad, a medio tiempo con organizaciones de la sociedad civil y asumí un papel activo en el litigio. La anticoncepción de emergencia fue claramente ese inicio. Haber llegado hasta la Corte Suprema en el año 2005, haber alegado ante la Corte Suprema en el 2005 como una tercera coayudante... O sea, hubo que pelear para llegar a la Suprema, hubo que pelear para que la sociedad civil fuera reconocida como un actor relevante frente al proceso, porque los demandantes no querían la presencia de organizaciones que defendieran la anticoncepción.

¡Qué interesante! Porque trabajé un paper el año pasado donde yo hablo de los laicos, los seculares y los confesionales. Así como yo dentro de la UDP estaba abocada en la defensa, quienes estaban demandando era los de la Universidad de Los Andes, entonces, allí había como una cosa bien interesante.

Llegar a la Suprema, no dedicarme al mundo del litigio, pero ocupar esas herramientas era importante; y después, en esa misma saga, llegar 
al Tribunal Constitucional en el año 2007-2008 y representar ahí a 52 diputados y diputadas en la defensa de la anticoncepción de emergencia y la norma nacional de regulación de fertilidad. Ese también fue un hito muy importante. El hecho de que 52 diputados te den el patrocinio y te digan: “Usted represéntenos"... y quizá, si lo miro en términos de continuidades, volver a cumplir ese rol contra el Tribunal Constitucional, después, por la lucha de la despenalización de las tres causales... también lo que el derecho representa tiene algo de simbólico.

Mariela Delgado: En cuanto a su historia y experiencia personal, ¿qué cree usted que ha incidido negativa o positivamente en su desarrollo profesional?

Lidia Casas: En el último libro que sacamos, en una parte hablamos de nuestras historias personales. Creo que muy tempranamente me gustaba hacer cosas distintas. En la universidad de Canadá también me dedicaba a investigar.

Que me ha marcado... quizá porque, no sé. Investigar es como aventurarte a conocer cosas y a contar historias. Provengo de una familia con una suerte de tradición oral, llevando la historia de los abuelos, llevando un poco eso, es contar historia; y luego, porque dentro de mi familia había historias y hay historias muy interesantes; es la historia particularmente de las mujeres la que es muy interesante. Uno podría verlas proyectadas, de cómo una las hace carne en la propia investigación que una realiza.

Mi ventaja ha sido tener una carrera previa al derecho, porque me dio un armado de las ciencias sociales distinto de la mirada súper unidireccional del mundo del derecho. Me permite mirar las ciencias sociales, pensar en cómo ayudan y yo me veo completamente distinta. Yo creo que esa es mi gran ventaja. La desventaja, quizá, puede sonar como contradictorio desde el punto de vista académico es no ser reconocida como alguien que viene del derecho duro, precisamente por la influencia de las otras ciencias sociales, porque mi forma de mirar lo que hago y cómo lo hago no es una mirada tradicional del derecho, que es mucho más de doctrina, dogmática, y yo constantemente estoy dialogando entre el derecho y la realidad. Entonces, eso me marca como académica. Puedo tener importantes reconocimientos en lo que yo persigo, en el tipo de trabajo que desarrollo, que es un trabajo socio- 
jurídico, pero a todo el mundo le cuesta mucho entender en qué parte de la tradición jurídica yo me encuentro, entonces, como que juega a favor, pero también en contra.

Mariela Delgado: Quiero entrar a un espacio más jurídico, ¿cuál es su visión de la justicia en Chile?

Lidia Casas: El sistema judicial, como aparato, en los últimos veinte años ha tenido inmensos avances que han permitido que, por ejemplo, en el mundo penal haya muchas más garantías que bajo el antiguo sistema. Esa es una cuestión que uno tiene que relevar: la posibilidad de ser representado por un abogado o abogada y no por estudiantes de derecho, gente que todavía no se recibe. Sin embargo, también hay elementos de eso en la nueva justicia laboral y de familia. Yo hablo de distintas justicias porque uno no puede hablar de la administración de la justicia como una cuestión monolítica, sino que hay muchas especificidades.

Los tribunales de familia son y siempre han sido en realidad los parientes pobres de la justicia. Se hizo una gran reforma con mucho menos recursos, como una copia un poco más débil del sistema penal. No tuvo un funcionamiento paulatino como lo fue en materia penal, sino que todo de un punto a otro y, por lo tanto, mostrando de forma inmediata todos los problemas que eso significa. Porque las causas de familia - salvo los divorcios-, en general, nunca terminan, incluso en la propia familia: peleas por la pensión de alimentos: que exijan un monto; después, no te lo pagan: tienes que cobrarlo; después el otro pide la rebaja de la pensión; después la discusión por el derecho de comunicación regular, es decir, las visitas, quién se queda con los niños... La familia constituye un núcleo de conflicto muy distinto al núcleo de derecho penal y con una serie de complejidades que, si bien tratan de acuerdo, finalmente no resulta fluido.

Luego, en la justicia laboral ha habido importantes modificaciones, también, con la existencia de jueces, de abogados profesionales. En el caso de familia, con eso hablo de los pobres del sistema, quedaron los resabios de que los estudiantes en práctica postulantes tengan la posibilidad de comparecer ante las audiencias de los juicios de familia. Ahora, insisto, esto no quiere decir que no haya avances importantes, pero hay déficits que son relevantes: corporaciones de asistencia judicial que tienen que atender a una gran cantidad de población, en 
algunos casos de familia y en otros temas civiles sin el profesionalismo que la gente se merece.

Luego, hay otras modificaciones, como la justicia bajo el antiguo sistema, que son básicamente los casos de violaciones a los derechos humanos durante la dictadura que están ahí, que están con sus propias lógicas, que siguen dando vueltas muchos años, incluso del noventa en adelante, más de treinta años en espera de resultados de sus procesos en los que se discute, sale en las noticias; en los que se busca que los violadores de derechos humanos puedan tener indulto, puedan salir en libertad. Uno tiene que mirar la justicia a través de distintos niveles, qué es lo que significa para un trabajador o trabajadora. En su proceso, la justicia se inicia antes, en el trabajo, en los tribunales de familia, en un largo proceso para llegar a la primera audiencia y juicio — en materia penal, con bastante rapidez en el inicio, y puede que algunas causas se demoren más.

Hay otras áreas que son nuevas, como la justicia ambiental. En realidad, conozco mucho menos, pero ahí uno podría decir que hay grupos en situación de desventaja, que son las comunidades: ¿qué posibilidades tienen las comunidades de tener una representación judicial de calidad que permita pelear contra las empresas en oposición a proyectos mineros, al uso del agua, de la tierra e impactos ambientales de distintos proyectos de explotación?

Mariela Delgado: ¿Qué opinión tiene usted de los jueces, de sus perfiles, de la formación que ellos tienen y sobre todo del impacto que tienen sus sentencias en la sociedad?

Lidia Casas: Como parte del proceso de recuperación democrática y bastante reconstrucción de un sistema de justicia completamente ilegitimado, durante el gobierno de Eduardo Frei Ruiz-Tagle se inicia una discusión importante sobre la carrera judicial. Para ser juez en Chile, en ese minuto, solo bastaba con ser abogado o abogada y luego tener algún pariente en el poder judicial. Es decir, existía el nepotismo como un elemento fundamental de la carrera judicial.

La creación de la carrera judicial a mediados de los años 90, 95, 96 da un inicio para crear primero una carrera, en la que para poder ingresar al Poder Judicial se requería un periodo de formación adicional, no solo de recibirse en la Facultad de Derecho. 
Yo conocí esto de alguna manera en sus inicios (a propósito de mi periodo de ayudante de Jorge Correa Sutil). Primero, indagando sobre cuáles eran las necesidades de los funcionarios judiciales, y después de esa primera etapa conociendo tribunales desde Antofagasta hasta Maullín, en el sur de Chile, en capitales de regiones y pueblitos. Entonces, como que tengo también en el cuerpo una cierta visión. Lo que en un minuto el mundo judicial antiguo rechazaba, luego algunos jueces jóvenes lo miraban con muy buenos ojos.

El inicio de esa academia judicial fue muy exitoso, porque yo creo que el trabajo fue pensar en que aquí había que dar un vuelco y que el control sobre la formación judicial tenía que romper con la cultura judicial, porque es como cuando ingresas a una institución; finalmente, tú puedes traer muchas cosas buenas de la formación previa, pero la cultura organizacional al final te moldea. Yo creo que con el paso de los años -y al término de la primera formación judicial, que fue una formación muy exitosa-nuevamente la Corte Suprema comenzó a tener más poder al interior de la academia judicial, con lo cual nuevamente volvieron a darse cursos impartidos por jueces a quienes iban a ser jueces. Se instalaba con eso una idea de transmisión de cultura judicial que quizá alguna vez se quiso romper. Yo creo que ahí hay un problema: la práctica de jueces dictando clases sin que se mezcle una mirada crítica respecto de su propia práctica de juez.

En la medida en que han entrado más personas en las escuelas de derecho, la academia judicial fue un lugar apetecido como un lugar de empleo. Yo no sé exactamente hoy día en qué está, pero las primeras generaciones fueron extremadamente selectivas en cuanto a la preparación de sus primeros jueces. Claramente, la gente que ingresaba, por ejemplo, a la fiscalía nacional, la mayoría de ellos había pasado por la academia judicial; los jueces ingresaban al proceso de reforma, a justicia penal también. O sea, hubo un proceso muy fuerte de capacitación, de sensibilización, y yo no sé cuánto ha decaído eso en los últimos años ni tengo tan claro el perfil, porque a veces yo me pregunto qué es lo que se busca, qué es lo que se quiere. El Poder Judicial es una institución súper jerarquizada, en donde, de alguna manera, muchos jueces en primera instancia miran hacia la Corte de Apelaciones, a las relaciones de sus superiores inmediatos, si sus resoluciones judiciales van a ser bienvenidas o no; hay algunos que son muy díscolos y 
que siempre están a contra pelo de sus superiores jerárquicos. Hay una cuestión de transmisión de jerarquía, donde muchos jueces pelean por su independencia, por la posibilidad de decidir sin estar constantemente mirando al superior.

Mariela Delgado: En ese sentido, relacionándolo con sus trabajos y las contribuciones que ha realizado en cuanto a género, ¿usted nota alguna diferencia entre los dictámenes entre jueces hombres y juezas mujeres?

Lidia Casas: En materia penal, hicimos un estudio por ahí por el 2003-2004, y mi impresión era que había más hombres que mujeres en el sistema penal, por lo tanto, era difícil poder tomar algunas decisiones. En esos primeros años, además, la fiscalía no llevaba tantos casos a juicio, más bien llevaban aquellos casos que tenían como ganados; y había muchas salidas alternativas, por lo tanto, uno no podía mirar las decisiones judiciales. Lo que yo podía advertir no era la diferencia de sexo sino los grupos etarios. Yo creo que ahí había miradas nuevas y, finalmente por tipo de universidad.

Una entrevista que me marcó, pero que no tenía que ver con violencia de género, tenía que ver, precisamente, con un estudio para la academia judicial para el que una compañera y yo tuvimos que ir a Freirina. Mi colega iba a hacer la entrevista a los funcionarios y a mí me tocaba entrevistar al juez y a la secretaria del tribunal, y el juez me preguntó (un tipo muy joven que no tenía más de 45 años) si yo estaba titulada o no, a lo que yo le dije que no, y su respuesta fue: "Demasiada personalidad para no tener título". Después hubo otra pregunta, y a mi colega, que iba de pantalón, él le dijo: "En la universidad donde yo me formé, una mujer no puede ingresar a clases con pantalón". No sé qué le habré dicho, pero él me respondió: "Una persona como usted no habría pasado a segundo año".

Había una animadversión muy evidente. Primero, en lo que significaba el trabajo en la carrera judicial (así como lo viví en Freirina, lo viví también en San Antonio y Temuco) había una resistencia, y en el caso de este juez, era evidentemente de misoginia. Él jamás, yo creo, se hubiera atrevido a decirle algo así a un hombre que lo hubiese ido a entrevistar, su actitud habría sido distinta. Yo creo que eso marca la forma en que muchas veces el mundo judicial veía a otras mujeres y veía, además, los cambios que se venían, entonces es de mucha resistencia. 
En Temuco el juez me dejó esperando afuera del despacho por más una hora y había una marcha en la plaza de Temuco (estamos hablando de los 90). Cuando se hablaba de mapuches, él se refería a los indios. Es muy marcado todo en estas cuestiones sociales de impacto muy grande. El juez de San Antonio me decía que las clases que hacia Jorge Correa Sutil y el magistrado Carlos Cerda no servían para nada (clases sobre razonamiento judicial), porque lo que había que tener claro era que había que tener bajo perfil y no mostrarse a través de la sentencia.

Estos tres ejemplos eran de varones y la mayoría de los que me tocó entrevistar eran varones en esa época, y había una impronta muy fuerte. Entonces, la cultura era una de mucha resistencia al cambio en algunos sectores; y en el caso de violencia yo no podría decir que las mujeres son más duras o más blandas. En el último año he entrevistado a jueces y fiscales, y ellos sienten que las mujeres deben ser más rudas que los jueces hombres para tener validación, pero eso no significa rudeza en términos de estándares de lo que le piden a los fiscales en cuanto a las condenas. Sería interesante saber cómo se da en la práctica.

Mariela Delgado: Qué interesante me parece cuando usted habla de cómo impera la institución en las conciencias y propias conductas de quienes se desempeñan en el poder judicial.

Lidia Casas: El mundo judicial más joven dice que eso se nota. Entre los jueces más jóvenes se notan las culturas educacionales de donde vienen por la manera de ver el derecho. Si son de escuelas más conservadoras, más liberales...

Mariela Delgado: Ahora pasemos a temas de contingencia. En este último tiempo con respecto a la crisis sanitaria han ido aumentando las denuncias por violencia intrafamiliar. Me gustaría saber, qué cree usted que debería hacer el Estado para hacerle frente a una situación de este tipo.

Lidia Casas: Lo he dicho en otras ocasiones. Hay que tener un trabajo con las comunidades y eso significa un trabajo real con los gobiernos locales que son los que tienen la más rápida respuesta frente a situaciones críticas; son los vecinos los que están ahí para poder responder; pero también el municipio debe contar con redes que le permitan responder. Las casas de acogida son una respuesta muy acotada. Lo que uno debería pensar como medida de protección para mujeres 
e hijos es sacar a esas mujeres. No es por la idea del riesgo inminente sino porque no está en condiciones de salir e irse a otro lado.

En algunos países, lo que han hecho es utilizar los hoteles, los hostales, las pensiones para dar refugio a las mujeres y sus hijos, pero advierto, hoy día, con harto pesar que el gobierno ni siquiera ha ampliado esas ofertas para hostales sanitarios, eso debería pensarse como una medida que le permite a muchas mujeres poder salir de situaciones. El segundo tiene que ver con un trabajo de red eficaz. Yo no sé de qué manera hoy día el Servicio Nacional de la Mujer y Equidad de Género está trabajando verdaderamente con los municipios o los centros de violencia. Lamentablemente, los centros de violencia tienen un nivel de precariedad importantísimo, y lo que ha sucedido con ellos para mí no está claro, en cuanto a cómo le hacen seguimiento a las causas y a las mujeres que están con medidas de protección. Yo siento que a veces hay mucho ruido y pocas nueces; nunca está muy clara la bajada de políticas públicas, que ya estaba muy debilitada, pero con la pandemia aflora: la precariedad se muestra en gloria y majestad.

Lo otro es una labor muy concreta de parte de los fiscales y, en entendimiento muy claro, de parte de los jueces. El caso de esta mujer que fue asesinada en La Serena es un caso, a mi juicio, de una muerte totalmente evitable. Ella venía pidiendo en forma sostenida medidas de protección que no fueron otorgadas por el ministerio público, que no tuvo severidad frente a lo que ella estaba pidiendo, hasta que fue asesinada. Yo digo, en una columna de opinión, que existe una cultura refractaria de los operadores de justicia al no advertir los contextos. En el caso particular, yo lo llamo sujeto contumaz, no tiene uno, sino varios más episodios de denuncias de violencia dentro del sistema, una denuncia tras otra. Entonces, cuando uno ve aquello el sistema tiene que ser capaz de reaccionar con mucha mayor severidad. A veces hay desgaste de parte de los fiscales. El no reconocimiento de que estas causas puede conllevar la muerte de personas y a creer que estos son conflictos de poca monta social. De hecho, aquí hablan de los delitos de gran connotación y gran violencia, pero no están hablando de la gran cantidad de casos que se están registrando. Ese pareciera ser otro tipo de violencia de la cual no nos estamos ocupando. 
Mariela Delgado: ¿Usted cree que el Estado ha sido capaz de cumplir con los tratados internacionales que existen en cuanto a protección de la mujer (Belén do Pará o los mismos ODS)?

Lidia Casas: Yo creo que no. Hay una serie de déficits que se producen por el comportamiento, por ejemplo, del fiscal de La Serena o con lo que sucede hoy día con la atención a víctimas de violencia sexual con resultado de embarazo, Yo creo que no hay. Cada pequeño avance es a partir de una gran lucha, pero después de esa gran lucha por ese pequeño avance se requiere de un nivel de energía muy grande para poder implementar y asegurar esos logros. Como que en Chile nos quedamos con los grandes titulares, pero sin ninguna bajada $y$, en este sentido, a mí me parece que ahí es donde empezamos a estar al debe. Yo creo que un buen símil es lo que hizo el presidente Piñera anoche, en donde anuncia por cadena nacional que van a repartir 2.5 millones de canastas con comida para los chilenos. ¿Qué hace la gente? Va y se coloca en fila frente a una municipalidad esperando que llegue la comida. Bueno, todavía esperan seguir desarrollando ese plan en una semana más. Entonces, hay unos niveles de expectativas con un gran titular sin un desarrollo y una bajada. Planteamos ciertas cosas, como: "Mujer, no tengas miedo", "mujer, denuncia”, pero finalmente no existe una red de soporte que le permita a la mujer sostener una denuncia o renunciar a esa relación. Ahora, la situación postpandemia será una situación muy, muy compleja para las mujeres, porque el nivel de cesantía en la informalidad es posible que mantenga a muchas más mujeres en situación de tener que mantenerse en relaciones violentas solo para resolver temas de supervivencia para ella y su familia.

Mariela Delgado: Pienso que el tipo de violencia que se verá con mayor fuerza después de la pandemia será la violencia económica.

\section{Lidia Casas: ¡Sí!}

Mariela Delgado: Usted es directora del Centro de Derechos Humanos de la Universidad Diego Portales donde publican un informe anual sobre derechos humanos. En el informe de 2019 quedó en evidencia la discriminación estructural que existe en el acceso de los derechos sociales. Este informe, si bien no tomó en cuenta el estallido social, en ese sentido me gustaría preguntarle ¿por qué cree usted que 
en Chile seguimos estando debajo de los estándares en la protección de los derechos fundamentales?

Lidia Casas: Creo que no hay país en donde no haya vulneración de los derechos. La idea del paraíso o de los escandinavos, y como dijo el ministro Briones: “Nosotros no somos Noruega"... Primero, porque hay conjunto de derechos que están anclados en una cierta capacidad del Estado de responder a necesidades, y uno puede mirarlo desde las más tradicionales nomenclaturas entre derechos civiles y políticos, y entre derechos económicos, sociales y culturales, pero el ejercicio de derechos requiere siempre de inversión pública y cuando no hay reconocimiento de la necesidad de inversión pública, los derechos se debilitan. Si yo quiero un derecho a la defensa, yo tengo que invertir en que la Defensoría Penal Pública tenga los recursos suficientes y adecuados para tener los profesionales que puedan atender de una manera competente a la población que necesita asistencia letrada. Por eso digo que hay dos justicias distintas: la penal, que tiene abogados y la familiar, para la que existen postulantes de derecho que tienen que hacer trabajos gratuitos y voluntarios por al menos seis meses sin ninguna capacitación y con escasa supervisión. Entonces, eso se llama ausencia de inversión para asegurar un derecho tan básico como el derecho a la defensa o el acceso a la justicia.

Eso se ve con mucha más fuerza en derechos económicos y sociales, en donde el modelo de derecho constitucional chileno es de Estado subsidiario, en donde el rol del Estado es secundario y en donde la sociedad civil es la que tiene la primera labor de proveer, servir y asegurar. Yo creo que lo que ha pasado con el estallido social, primero, y con la pandemia, ahora, resulta ser una explosión de lo que se venía acumulando. Tú puedes ver que nosotros subimos a la página web todas nuestras recomendaciones en materia de derechos económicos en los últimos diez años, y vamos dando cuenta de eso que tú llamas desigualdades estructurales, aquella precariedad que hoy día se muestra con toda su fuerza, trabajadoras de casa particular que no tienen derecho a un seguro de cesantía. Entonces, lo que quiero decir aquí es que cuando no hay conciencia de que tienes que invertir en derechos sociales y económicos (porque no tenemos la conciencia que tiene Noruega para invertir en la protección de derechos)... .

Mariela Delgado: Ahí se vuelve a la discusión de las expectativas v/s realidad, en cómo hacer bajar esos grandes títulos a las personas. 
En el último tiempo se ha ido generando una discusión respecto al rol que tienen los deberes constitucionales en la sociedad.

Lidia Casas: Los deberes constitucionales son básicamente algunas partes que establecen la constitución: honrar tu patria; símbolos patrios; realizar el servicio militar obligatorio; eventualmente, lo fue votar como una carga; pero el derecho fundamental no tiene un deber asociado: es un derecho que tenemos las personas frente al Estado. Yo, para tener el derecho a la salud, el Estado no me lo puede condicionar a que yo sea una buena persona; se me debe garantizar el derecho a la salud.

Una persona privada de libertad y que está condenada por un delito tienen un derecho a la salud, independiente de cuán malo haya sido, entonces, no hay ahí una contrapartida.

Mariela Delgado: Nosotros postergamos un plebiscito de entrada para un eventual cambio de constitución, que está pospuesto por la crisis sanitaria. En el caso de que la ciudadanía optara por un cambio de constitución, ¿qué cree usted que este nuevo pacto social debería consagrar?

Lidia Casas: Una de las primeras cosas que debería suceder es el reconocimiento a los pueblos originarios. Eso no se pudo hacer en la reforma constitucional del 2005; eso es algo que la sociedad chilena ha evadido y hemos visto que han pasado más de 500 años y no se puede seguir mirando el techo como si no existiera. La segunda es priorizar los derechos económicos y sociales dentro del texto constitucional y, yo diría, asegurar con mucha claridad los derechos sexuales y reproductivos de las mujeres. Hay un tema que no será menor y es la consagración del derecho al agua: esa será la pelea más dura. Los intereses que existen sobre los derechos al agua, a eso nos hemos referido en el Informe Anual sobre la situación del agua. Nuestro nuevo informe anual será "Entre estallido social y covid-19", obviamente por la contingencia, pero creemos que tenemos que ir mirando nuestra agenda social entre los derechos y lo que se viene. 